\title{
A RARE CASE OF LEFT SIDED SPIGELIAN HERNIA
}

\author{
Rajshekar Patil ${ }^{1}$, Palla Abhishek Reddy², Vishal Kadeli ${ }^{3}$
}

\section{HOW TO CITE THIS ARTICLE:}

Rajshekar Patil, Palla Abhishek Reddy, Vishal Kadeli. "A Rare Case of Left Sided Spigelian Hernia". Journal of Evolution of Medical and Dental Sciences 2014; Vol. 3, Issue 13, March 31; Page: 3512-3515,

DOI: $10.14260 /$ jemds $/ 2014 / 2312$

CASE REPORT: A case of Spigelian hernia in a 70-year-old female patient was diagnosed clinically and treated by surgical repair. The patient had an uneventful postoperative recovery. It is being reported and the relevant anatomical and clinical details and current management are being reviewed.

KEYWORDS: Spigelian hernia, Interstitial Hernia, Spigelian Fascia.

INTRODUCTION: Spigelian hernia is named after Belgian anatomist Adriaen van den spigehel who described the semilunar line (linea spigeli). However it was first described and defined after Josef Klinkosch in $1764^{1}$ spigelian hernia is protrusion of preperitoneal fat, peritoneal sac, or viscera through a congenital or acquired defect in spigelian aponeurosis. Frequently presents between 50-70 years of age, male: female ratio is 1:1.18 \& occurs twice as often as on right side compared to left side. Reported incarceration case is $17 \%$, with acute presentation in $10 \%$ \& lack of physical findings in $36 \% .^{2}$

They are uncommon and only about 1000 cases have been reported in the literature. ${ }^{3}$ This case is being reported because of its rarity. These are the hernias representing $1 \%-2 \%$ of all abdominal hernias. Accurate prospective diagnosis of this condition is difficult because of the physical presence of these hernias is often not demonstrable owing to its peculiar anatomic location. Many patients of spigelian hernia therefore may have no obvious findings on clinical examination. The diagnosis is even more difficult in obese people where in the hernial sac may lie in an intraparietal plane masked by abdominal subcutaneous fat ${ }^{3}$.

CASE REPORT: A 70-year-old female presented with a large, painful lump in the left lower abdomen of approximately 15 years duration (fig. 1). The lump had gradually increased in size and become more prominent on standing up and straining. There was no history of local trauma or indicative of intestinal obstruction. Physical examination revealed an elderly patient in satisfactory general health with hypertension.

The anterior abdominal wall showed a swelling in its infraumbilical portion along the lateral border of the right rectus abdominis muscle. It measured $15 \mathrm{~cm} \times 5 \mathrm{~cm}$ and was more prominent in the upright position. Local tenderness and cough impulse was absent and it was partially reducible. A diagnosis of Spigelian hernia was made and the patient was taken up for surgery under general anesthesia.

A transverse incision was made over the swelling. The external oblique aponeurosis was split and the hernial sac was found lying beneath it (fig. 2). The sac was dissected out and opened - The content of the sac was bowel loops (fig. 3). The sac was excised and the defect in the Spigelian fascia and the internal oblique muscle was repaired using $2 / 0$ polypropylene (fig. 4). The patient had an uneventful postoperative recovery. 


\section{CASE REPORT}

DISCUSSION: The exact etiology of spigelian hernia is uncertain.it could be either congenital or acquired $^{3}$ the congenital theory suggest that the spigelian fascia is weakened by the presence of perforating vessels, which predispose to herniation. Acquired causes can suggest weakening of the abdominal wall due to collagen disorders, ageing, obesity, rapid weight loss, multiple pregnancies, trauma, surgeries. The contents commonly include pre-peritoneal fat, omentum, bowel \& occasionally organs Adriaan Van Den Spieghel (1578 - 1625), Professor of Surgery and Anatomy at Padua first described the semilunar line which marks the transition from muscle to aponeurosis in the transverse abdominis muscle and stretches from the costal arch to the pubic tubercle.

The part of the aponeurosis that lies between the semilunar line and the lateral edge of the rectus muscle is called the Spigelian fascia. ${ }^{3}$ Most Spigelian hernias occur in the area between the level of the umbilicus and the arcuate line or fold of Douglas, particularly at the point where the semilunar and arcuate lines meet.

There is no posterior rectus sheath below this point and the rearrangement of the fibres at this point is believed to cause an area of functional weakness through which herniation can occur. ${ }^{3}$ Usually the sac lies in the loose areolar tissue between the internal oblique and the external oblique muscles and enlarges laterally. The rectus sheath inhibits medial enlargement. Sometimes the sac may lie below the internal oblique muscle and rarely subcutaneously, above the external oblique. ${ }^{3}$

The commonest age of presentation is between the 40 and 70 years. 2 however cases have been reported in infants and children. The usual complaints are pain or lump or both at the site of herniation. Features of intestinal obstruction may be present. A localized perforation in to the sac may present as an abdominal wall abscess fistula. ${ }^{3}$

The diagnosis is made clinically and may be confirmed by ultrasonography. . Radiographic examination using plain film and contrast media is generally unsatisfactory. Ultrasonography is easier to perform, is cheaper and does not involve exposure to radiation and represents the gold standard in the diagnosis of Spigelian hernia. ${ }^{4}$

The latter is preferred only when more information regarding contents of the hernial sac is desired.

The use of intra operative ultrasonography for the localization of the hernial sac in obese patients has also been reported.

The treatment of a Spigelian hernia is by operative repair. For palpable hernias a grid incision is recommended and for non-palpable cases a pre-peritoneal approach via a vertical incision is advocated. ${ }^{4}$ Laparoscopic repair of Spigelian Hernia has also been reported 4 and is likely to be more widely used in the future. Recently a new technique which utilizes a pre-shaped polypropylene umbrella type plug for a tension free occlusion of the hernia ring has also been described. 5

In conclusion the possibility of a Spigelian Hernia must be considered in any patient presenting with persistent localized pain or a vague lump in the lower abdomen just lateral to the outer border of the rectus muscle. ${ }^{6}$ This helps in reaching an early diagnosis and proper management in these patients. Sometimes the hernia occurs below the level of the arcuate line and is then called "low" Spigelian hernia. Other hernias such as umbilical, epigastric and inguinal may sometime coexist $^{7}$ 


\section{CASE REPORT}

\section{REFERENCES:}

1. D.W.Larson, D.R Rarley. Spigelian hernia: repair \&outcome for 81 patients. World Journal of Surgery, vol 26, no.10, pp1277-1281, 2002.

2. Sanchez-Montes I, Deysine M. Spigelian hernias. A new repair technique using preshaped polypropylene umbrella plugs. Arch Surg 1998; 133: 670-2

3. Spangen L. Spigelian Hernia. In Nyhus LM and Condon RF. Ed. Hernia, $4^{\text {th }}$ ed. Philadelphia: J. B. Lippincott Company, 1995; 381-392

4. Torzilli G, Carmana G, Lumachi V et al. The Usefulness of ultrasonography in diagnosis of the Spigelian hernia. Int Surg 1995; 80: 280-2.

5. Kasirajan K, Lopez J, Lopez R. Laparoscopic technique in the management of Spigelian hernia. J Laparoendosc Adv Surg Tech 1997; 7: 385- 8.

6. Spagen. Spigelian hernia. World Journal of Surgery, vol 13, no.5, pp 573-580, 1989

7. Y. Weiss, O.Z.Lernau, \& S. Nissan. Spigelian Hernia. Annals of Surgery, vol.180, no.6, pp.836-839, 1974

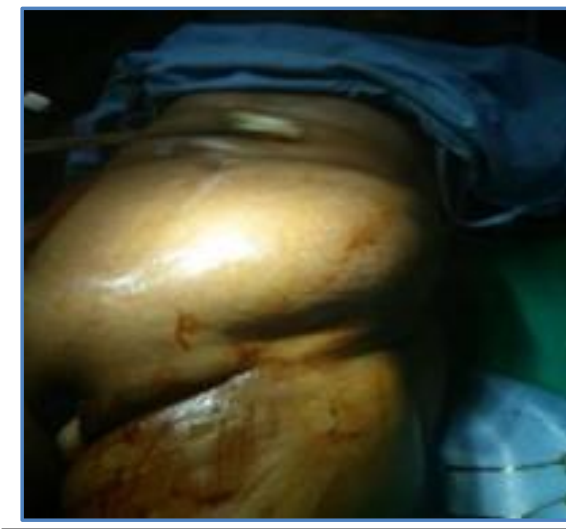

Fig. 1: Large abdominal hernia

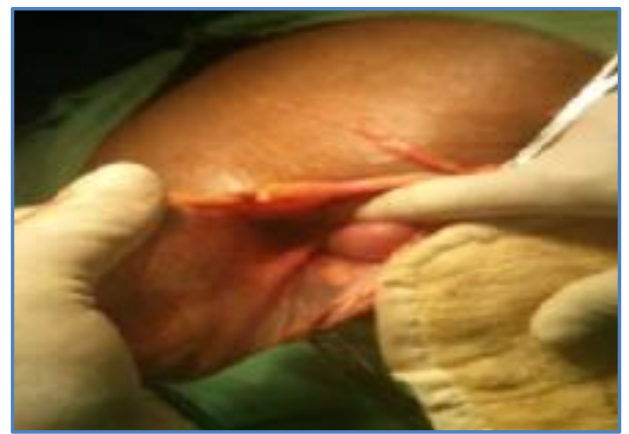

Fig. 3: Defect in the external oblique aponeurosis

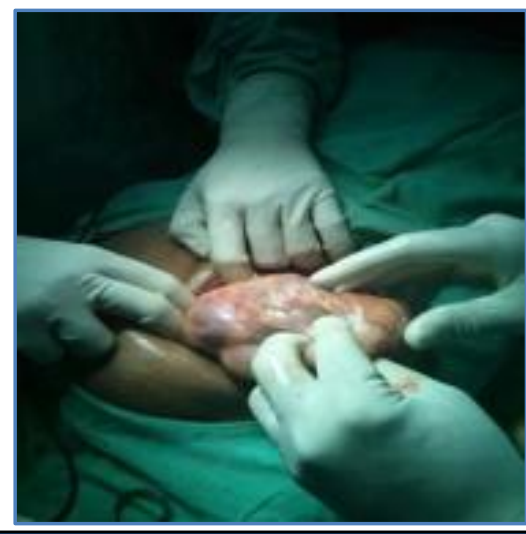

Fig. 2: Sac showing bowel contents

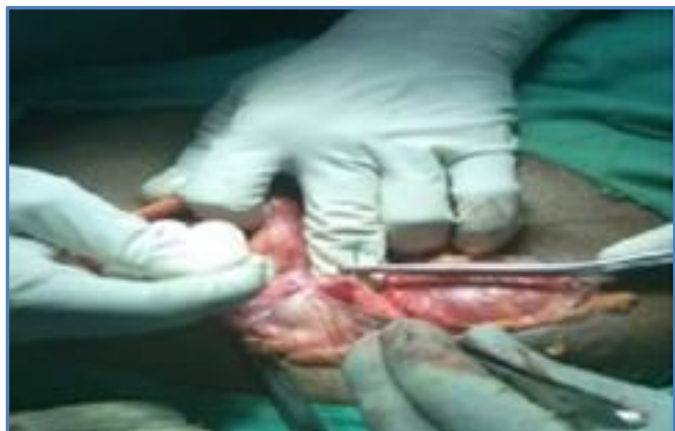

Fig. 4: Defect closed with 2-0 polyproplene 


\section{CASE REPORT}

\section{AUTHORS:}

1. Rajshekar Patil

2. Palla Abhishek Reddy

3. Vishal Kadeli

\section{PARTICULARS OF CONTRIBUTORS:}

1. Associate Professor, Department General Surgery, M.R.M.C and Basweshwar Teaching Hospital, Gulbarga.

2. Resident, Department General Surgery, M.R.M.C and Basweshwar Teaching Hospital, Gulbarga.

3. Resident, Department General Surgery, M.R.M.C and Basweshwar Teaching Hospital, Gulbarga.

\section{NAME ADDRESS EMAIL ID OF THE CORRESPONDING AUTHOR:}

Dr. Rajshekar Patil,

Block No - 56, Swastik Nagar,

Bilgundi Layout, Sedam Road,

Gulbarga - 585105.

E-mail: drrjsp@gmail.com

Date of Submission: 04/03/2014.

Date of Peer Review: 05/03/2014.

Date of Acceptance: 13/03/2014.

Date of Publishing: 29/03/2014. 